Farm animal welfare - who writes the rules?

Occasional Publication No. 23 - British Society of Animal Science 1999

edited by A. J. F. Russel, C. A. Morgan, C. J. Savory, M. C. Appleby and T. L. J. Lawrence

\title{
Who are the consumers of farm animal welfare?
}

\author{
R. M. Bennett and R. J. P. Blaney \\ Department of Agricultural and Food Economics, University of Reading, Reading RG6 6AR
}

\section{Introduction}

There are inextricable linkages between the disciplines of animal science, moral philosophy and economics when studying the welfare of farm animals. The task facing economists is to translate farm animal welfare into an economic concept and so be able to analyse it within an economic framework. Within economic theory farm animals may be viewed as no more than agricultural products, which represents the ethical position that animal welfare is only important as far as it impacts on human welfare. Thus, the following approach is appropriate: people are faced with choices which they may act upon individually or collectively and one choice to be made is about the level of farm animal suffering perceived to be acceptable. This may be characterized as a trade-off between farm animal products and perceived farm animal welfare. The value of farm animal products can be indicated by their prices but the value of farm animal welfare to society may not be fully recognized. Although consumers may respond to their farm animal welfare concerns by buying products perceived to be associated with higher levels of animal welfare they may stop buying some animal products altogether. Therefore, their preference for a high level of farm animal welfare will not be taken into account by the market. This under-recognition of people's true values can lead to poor farm animal welfare. Therefore, to optimize the production of various farm animal products within society the true value of farm animal welfare must be estimated. This involves taking account of the values to both consumers and non-consumers of farm animal products (Bennett, 1995). To enable measurement of society's valuation of farm animal welfare various economic tools can be used, one of which is contingent valuation. Although this methodology has theoretical and practical problems, its application to farm animal welfare issues has been explored (Bennett and Larson, 1996) and may provide a useful input to the farm animal welfare debate. The aim of this experiment was to determine how people's attitudes and moral beliefs concerning farm animal welfare affect the value they place on farm animal welfare improvements.

\section{Material and methods}

A contingent valuation survey of 120 undergraduate students at the University of Reading was conducted during the 1998 summer term. The students were from the Department of Economics and the Department of Psychology and were given the contingent valuation questionnaire to complete in class. The questionnaires consisted of three sections and the farm animal welfare scenario chosen to elicit valuations was pig slaughtering. The first section asked the students questions about their age, sex, nationality, and their existing purchasing behaviour with regard to animal products. It then asked them to score on a scale of 0 to 10 the importance of six farm animal welfare issues, with 10 being 'very important'. The second section provided information about the existing pig slaughtering techniques used in the UK, including some of the potential animal welfare problems and alternative 'humane' slaughter techniques. The students were then asked whether they would support government legislation to make it compulsory for slaughterhouses to use the 'humane' pig slaughter techniques (i.e. the head-toback system). They were then asked the amount of money they would be willing to pay, as an increase in their weekly food bill, to support this legislation (a single-bounded dichotomous choice format was used, with amounts ranging from $25 p$ to $£ 2$ ). The third section asked the students eight related attitudinal questions, which they were asked to score on a scale of 0 to 10 , with 10 being 'very much like my way of thinking'. These attitudinal questions also included questions about the morality of the pig slaughtering techniques. Finally, the students were asked to state their considerations behind the scores they gave.

\section{Results}

Of the two groups sampled, 64 psychology students and 48 economics students completed the questionnaires. The age range of the students was 18 to 35 years; $8 \%$ of the students were from outside the UK and $5 \%$ were vegetarian. The gender profile was $60 \%$ female, $40 \%$ male. The mean expenditure on food consumption was $£ 24 \cdot 78$ per week. In response 
to the question: to what extent are you concerned that farm animals may be mistreated or may suffer in the process of producing food/agricultural products?' the mean score of 'concern' was 2.7 (s.d. 0.94 ) on a scale of 0 to 4 , indicating that they were only somewhat concerned. However, when asked whether they agreed that: 'it is morally wrong to cause harm animals any pain or injury for the purposes of producing food' the mean score on the agreement scale of 0 to 10 was 6.8 (s.d. 2.35), indicating agreement with the statement that it is morally wrong.

The most important animal welfare issues were identified as hens kept in battery cages, pig slaughter without adequate stunning, and live exports (Table 1).

Just over $61 \%$ of the sample population supported the proposed pig slaughter legislation and $15 \%$ were against, with a mean willingness to pay (WTP) to support the legislation of 60p per week (i.e. 0.60 , s.d. 0.69 ). This is equivalent to a $2.4 \%$ increase in food expenditure. The WTP was higher for females $(0.72$ v. 0.44 ; s.e.d. $0.09 ; P<0.05)$, psychology students $(0.77$ v. 0.46 ; s.e.d. $0.10 ; P<0.05)$, and those already avoiding some animal products because of animal welfare concerns $(0.77 v .0 .41$; s.e.d. $0.09 ; P<0.01)$. About $20 \%$ of the sample population avoid buying some animal products because of their concerns about the welfare of the farm animals involved in those products. Spearman correlation analysis indicated correlations between WTP and age-group $(P<0.05)$, belief that it is morally wrong to cause farm animals any pain $(P<0.01)$, belief that pigs have a right to as painless death as possible $(P<0.001)$, belief that the current pig slaughter techniques are wrong $(P<0.001)$, belief that public

Table 1 'Importance' scoring of farm animal welfare issues

\begin{tabular}{lccc}
\hline \hline Animal welfare issue & Rank & Mean scoret & s.d. \\
\hline $\begin{array}{l}\text { Hens kept in battery cages } \\
\begin{array}{l}\text { Pig slaughter without adequate } \\
\text { stunning }\end{array}\end{array}$ & $(1)$ & 7.4 & 2.64 \\
$\begin{array}{l}\text { Live export of farm animals } \\
\text { from the UK }\end{array}$ & 3 & 7.4 & 2.51 \\
$\begin{array}{l}\text { Nose-ringing pigs to limit } \\
\text { field damage }\end{array}$ & 4 & 5.0 & 3.11 \\
$\begin{array}{l}\text { Castration of lambs with } \\
\text { rubber rings }\end{array}$ & 5 & 4.8 & 2.68 \\
$\begin{array}{l}\text { Use of high-yielding breeds } \\
\text { of dairy cows }\end{array}$ & 6 & 4.7 & 2.85 \\
\hline \hline
\end{tabular}

+ Note: the scoring was on a scale of $0-10$, with 10 indicating a 'very important issue', and 0 indicating 'not an important issues'. Thus, a mean score of 5 indicates 'neither an important nor unimportant issue'. opinion is that current pig slaughter techniques are wrong $(P<0.05)$ and concern about other farm animal welfare issues $(P<0.001$ to 0.05$)$. Of the attitudinal questions the most significant was: 'pigs have a right to die in as painless way as possible', which had a mean score (on a scale of 0 to 10) of 8.4 (s.d. 2.3), indicating strong agreement with the statement. The considerations the students stated were behind their scoring indicating that they had followed a reasoned and logical approach.

\section{Conclusions}

A higher valuation of pig welfare was associated with gender, age and course studied. This is in line with other studies that have shown that females are more ethical than males, that moral development is a function of age and that economics students are less concerned with moral issues than non-economists (Frank et al., 1993; Baron, 1994; Eckel and Grossman, 1998). A higher valuation of pig welfare was also associated with a high degree of perceived moral importance of farm animal welfare (and pig welfare in particular), other farm animal welfare concerns and a belief that there is consensus in society that current pig slaughter techniques are wrong (Table 2). These results support the validity of the contingent valuation methodology and the preliminary findings suggest that there is a positive link between attitudes and moral beliefs concerning farm animal welfare and the value people place on improvements in farm animal welfare.

Table 2 The most significant factors influencing students valuations of pig welfare

\begin{tabular}{lcc}
\hline \hline $\begin{array}{l}\text { Factor influencing } \\
\text { valuation }\end{array}$ & High valuation & Low valuation \\
\hline $\begin{array}{l}\text { Gender } \\
\begin{array}{l}\text { Course being studied } \\
\text { Age }\end{array}\end{array}$ & $\begin{array}{c}\text { Female } \\
\text { Psychology }\end{array}$ & $\begin{array}{c}\text { Male } \\
23\end{array}$ \\
$\begin{array}{l}\text { Ethical purchasing } \\
\text { behaviour }\end{array}$ & $\begin{array}{c}\text { Avoid some } \\
\text { animal products }\end{array}$ & 18 \\
$\begin{array}{c}\text { Farm animal } \\
\text { welfare issues } \\
\begin{array}{c}\text { Moral importance } \\
\text { of pig welfare }\end{array}\end{array}$ & Concerned & Not concerned \\
\hline \hline
\end{tabular}

\section{Acknowledgements}

R. J. P. Blaney is grateful to MAFF for the provision of a Ph.D. studentship.

\section{References}

Baron, J. 1994. Thinking and deciding, second edition. Cambridge University Press. 
Bennett, R. M. 1995. The value of farm animal welfare. Journal of Agricultural Economics 46: 46-60.

Bennett, R. M. and Larson, D. 1996. Contingent valuation of the perceived benefits of farm animal welfare legislation: an exploratory survey. Journal of Agricultural Economics 47: 224-235.
Eckel, C. and Grossman, P. 1998. Are women less selfish than men? Evidence from dictator experiments. The Economic Journal 108: 726-735.

Franc, R., Gilovich, T. and Regan, D. 1993. Does studying economics inhibit co-operation? Journal of Economic perspectives 7: 159-171. 